\title{
USING LINKOGRAPHY TO VISUALISE THE INFLUENCE OF EDUCATIONAL BACKGROUNDS ON COLLABORATION AND CREATIVITY IN IDEA GENERATION
}

\author{
Yuki TAOKA, Haruhiko MIHONO and Shigeki SAITO \\ Tokyo Institute of Technology
}

\begin{abstract}
Differences in disciplines are one kind of diversity, a well-supported factor to influence the degree of outcomes' creativity in design. It is needed to analyse design discussion in detail and evaluate outcomes to support idea generation by multi-disciplinary teams. Linkography has been developed to analyse and visualise design activities done by either individual or group. Linkography lets researchers connect design moves, described as a small unit of verbalisation lasting a few seconds in design activities. A total of 16 undergraduate and graduate students participated in the experiments. The participants were divided into groups of four participants. The participants conducted two group work sessions; one in the non-diverse group, which consists of four students either from art or engineering, and the other in the diverse group, consisting of two students from art and two from engineering. Within a session of the experiment, the participants generate and select ideas. This paper reports the first step of the session, which is a 10 minute idea generation. The experiment was analysed by three aspects: questionnaire assessing participants' self-reflection, design outcomes assessing the degree of creativity of outcome, and Linkography assessing group discussion dynamics. This paper aims to reveal multi-disciplinary group discussion dynamics in comparison to single-disciplinary teams during idea generation. Findings will be useful for academic researchers as well as educators and practitioners in design.
\end{abstract}

\section{Keywords: Multi-disciplinary team, Linkography, idea generation}

\section{INTRODUCTION}

In highly competitive markets, companies must develop innovative products or services. In this era, design education can play a critical role in making students acquire required competitiveness such as creativity [1]. In such a PBL course and product development in companies, it is necessary to have teams consisting of people from diversified backgrounds to develop innovative products [2]. However, an increasing degree of diversity in a team does not directly link to a higher quality of project outcomes. This fact increases the importance of understanding factors influencing both design projects and PBL, which are conducted by multi-disciplinary teams. The members' diversity allows diversified viewpoints, which determines the number of resources available to apply to the solution of the problem [3]. 'Diversity' in a team is divided into two categories: bio-demographic diversity and task-related diversity [4]. Both diversities are reported to have positive impacts on outcomes. Bio-demographic diversity represents characteristics that can be immediately observed and categorised, e.g., age, gender, and national culture. Increasing age diversity positively affects a company's productivity if the company works in creative industries rather than routine tasks [5]. A group with gender diversity generates more ideas and has more viewpoints on design topics than a group without gender diversity [6]. On the other hand, task-related diversity represents individual attributes that cannot be observed, e.g., education and expertise. Cognitive styles diversity and self-efficacy have positive impacts on design outcomes [7]. Disciplinary diversity in a team is a crucial factor for innovation and new knowledge [8]. Increasing disciplinary diversity can positively affect innovation's financial value, whereas merely increasing the degree of diversity in a team does not always increase the innovative value [2]. Although diversities' positive influence is reported, it is unclear what factors encourage the positive effect of diversity and what factors withdraw the drawback of diversity. Therefore, it is necessary to investigate discussion dynamics by visualising interaction between people having different disciplinary backgrounds. 
Linkography was initially developed as a method to visualise individual design activities by connecting design moves with a link node [9]. Goldschmidt (1995) defined a design move as 'a step, an act, an operation, which transforms the design situation relative to the state in which it was prior to that move' [10]. Figure 1 illustrate Linkography terminology. Evaluators find links between design moves based on "common sense" [11]. Link nodes visualise the links. 'Critical moves (CMs)' is one of the perspectives to interpret Linkography. CMs are design moves with a high number of link nodes. Links to proceedings moves are called fore-links, and links to preceding moves are called back-links. A high number of backlinks means that the design move was derived from or integrated with many previous moves, which is relevant to convergence, while a high number of fore-links means that the move inspired many future design moves, which is relevant to divergent thinking [12]. The application area has been expanded to team design activities, including design discussions [13, 14].

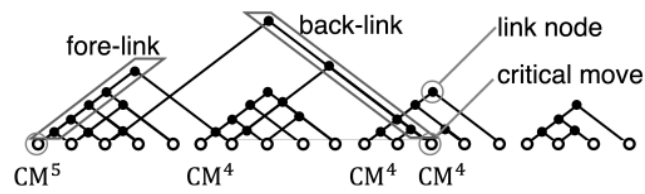

Figure 1. A Linkography illustrating terminology

This study's research question is how the degree of disciplinary diversity within a team impacts creativity of design outcomes and group discussion. This paper reports an investigation of an experiment that compares multi-disciplinary groups of art and engineering students in comparison to single-disciplinary teams of either art or engineering students during idea generation. The group discussion dynamics were investigated by the creation of Linkography.

\section{METHOD}

A total of 16 undergraduate and graduate students participated in the experiments. Half of the participants were enrolled in art universities, and the other half in engineering universities. The participants were divided into groups of four participants. The participants conducted two group work sessions; one in the non-diverse group (homogeneous): four students either from art or engineering, and the other in the diverse group (heterogeneous): two students from art and two from engineering. Within a session of the experiment, the participants generated and selected ideas. This paper reports the first step of the session, which is a 10 minute idea generation. Half of the participants conducted the session with a homogeneous group first, and then they conducted the other session with a heterogeneous group. The other half of the participants conducted the sessions in counterbalanced order. The first session's task was to "propose a service or product related to the reading experience for college students." The second session's task was to "propose a service or product related to the gift-giving experience for college students". The experiment was analysed by three aspects: questionnaire assessing participants' self-reflection, design outcomes assessing the degree of creativity of outcome, and Linkography assessing group dynamics. The questionnaire addressed to what extent each participant considered each aspect of creativity (novelty, usefulness, and feasibility) during idea generation.

The degree of creativity was assessed by the quality and fluency of ideas. The fluency was evaluated by counting the number of Post-it Notes the participants wrote down. Two trained evaluators evaluated the quality of ideas in terms of three criteria which are novelty, usefulness, and feasibility. Each of the ideas was shown to the evaluators with seven-point Likert scale questions addressing the three criteria where a higher score meant a stronger agreement. Originality was assessed with a question that "this idea is not only new, but also clever, imaginative, and unexpected". Usefulness was evaluated with a question that "this idea can be applied to the problem and will solve it efficiently". Feasibility was asked with a question that "this idea is feasible and can be easily implemented". Creativity evaluation of ideas was conducted by two trained evaluators, who were asked to evaluate the creativity of 30 ideas prepared in advance for practice multiple times until the Cronbach's alpha coefficient [15] became 0.7 or higher for each of the three scales. Next, the raters were asked to rate the creativity of the ideas remaining from the idea sorting process and then asked to discuss the ideas among themselves so that the difference in the rated scores among the raters would be within 1 [16]. The creativity of the ideas created was determined by averaging the creativity of the ideas modified by the discussion between the two raters.

The questionnaire was used to assess what participants thought during idea generation. The questionnaire had questions asking to what extent the participants pay attention to each of the three 
criteria of creativity. The questions were asked with seven-points Lickert scale questions such as "when you were thinking about an idea, did you pay attention to the originality of the idea?".

Linkography was used to visualise the dynamics of group discussion. Linkography identifies links among design moves. In this study, each conversation turn-taking was used as a design move $[13,17]$. In other words, each utterance was regarded as a design move. In this study, we chose to include backchanneling feedback such as "yeah" and "yes" because backchanneling feedback plays a significant role in moving conversation in the Japanese language [18]. In linking design moves, a guideline used by Hatcher [14] was used with minor modifications, which includes rules of words to be connected. After creating Linkography of the conversations, we applied codes as shown in table 1 to each design move relevant to the codes. For example, backchanneling feedbacks were not coded with the codes. The codes were developed based on the work of Hatcher [14]. Figure 2 shows an example of the result of Linkography and coding. In figure 2, backchanneling feedback was omitted for the sake of increasing the visibility of the figure. CMt denotes a design move with $t$ link nodes. The numbers of CM4, CM5, and CM6 were counted. We also counted the number of codes having each code.

The numbers of CM and codes and the result of questionnaire and creativity of outcomes were statistically analysed by nonparametric methods. We compare within students meaning the difference between the same students in homogeneous groups and heterogeneous groups and between students meaning the difference between students studying arts and studying engineering in either homogeneous or heterogeneous group.

Table 1. Categories of codes used for the analysis

\begin{tabular}{|c|c|c|}
\hline Category & $\begin{array}{c}\text { Sub- } \\
\text { category }\end{array}$ & Description \\
\hline \multirow{3}{*}{ Idea } & New & A novel idea \\
\hline & Incremental & $\begin{array}{c}\text { Back-link to a new idea, and the idea is considered as an improved } \\
\text { idea of the new idea }\end{array}$ \\
\hline & Tangential & $\begin{array}{l}\text { Back-link to a new idea, and the idea is considered as an expanded } \\
\text { or combined idea }\end{array}$ \\
\hline $\begin{array}{l}\text { Knowledg } \\
\text { e }\end{array}$ & & $\begin{array}{c}\text { Knowledge of existing products, the experience of a speaker, general } \\
\text { knowledge }\end{array}$ \\
\hline
\end{tabular}

\begin{tabular}{|c|c|c|c|c|c|}
\hline speakers & Engineer 3 & Engineer 3 & Art 1 & Engineer 3 & Engineer 3 \\
\hline codes & New & Incremental & Tangential & Incremental & Knowledge \\
\hline speech & $\begin{array}{c}\text { It's good to } \\
\text { choose and buy } \\
\text { products, but it's } \\
\text { also good to } \\
\text { make original or } \\
\text { kelf-made gifts. }\end{array}$ & $\begin{array}{c}\text { For example, a } \\
\text { picture of your a } \\
\text { friend's face on } \\
\text { it. }\end{array}$ & $\begin{array}{c}\text { Like a workshop } \\
\text { for making gifts. }\end{array}$ & $\begin{array}{c}\text { Maybe an A0 } \\
\text { size poster } \\
\text { made by a } \\
\text { friend. }\end{array}$ & $\begin{array}{c}\text { I had given it to } \\
\text { him in the past } \\
\text { when I was in } \\
\text { high school. }\end{array}$ \\
\hline
\end{tabular}

Figure 2. An example of Linkography and coding result

\section{RESULT}

\subsection{The assessment of outcomes and questionnaire}

Figure 3 shows the result of questionnaire analysis, and Figure 4 shows that the result of average fluency of each participant in idea generation and quality analysis of creativity. In figure 3 and figure 4, for example, "art students in homogeneous or in home" stands for the result of students studying in art university worked only with art students. Figure 3 shows that there was a significant difference in the attention of engineering students between the experiment's conditions. The result suggests that engineering students perceived that they paid more attention to ideas' originality during idea generation. Figure 4 (left) shows that there were significant differences between art students and engineering students in homogeneous groups and the difference between art students and engineering students in 
heterogeneous groups. The results indicate that art students generated more ideas than engineering students regardless of the experiment's conditions of the degree of diversity.

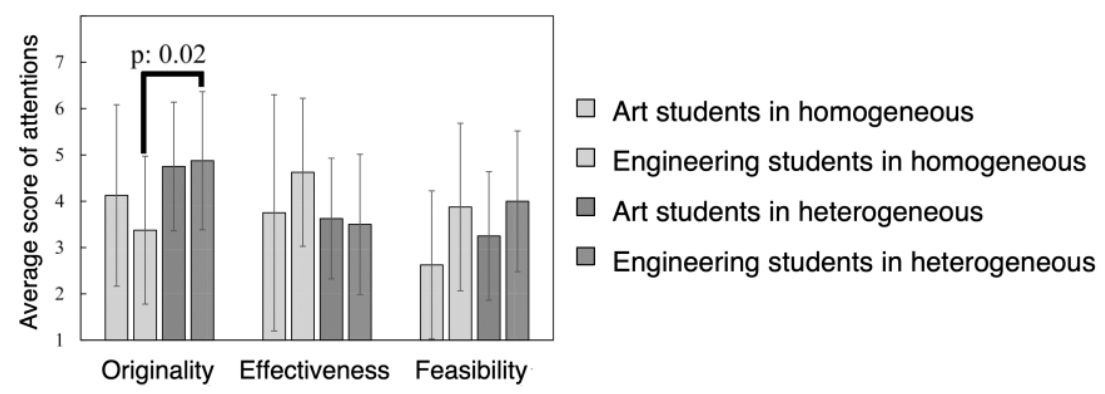

Figure 3. Result of questionnaire analysis

Figure 4 (right) shows the results of the assessment of the quality of ideas in terms of three criteria. There was a significant difference in art students between the experiment's conditions. The result indicates that art students generated ideas of less originality in the heterogeneous condition than in the homogeneous condition. There was no significant difference in other criteria.
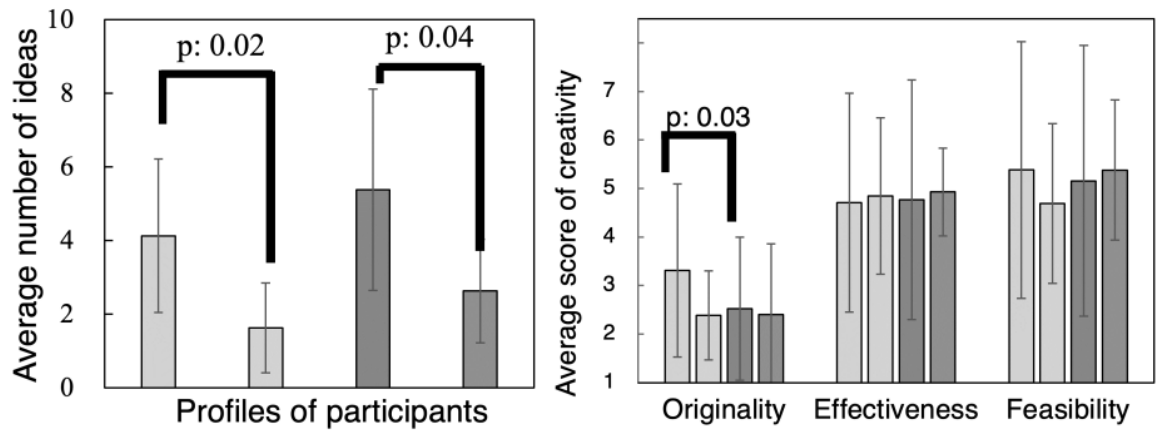

Figure 4. Result of creativity analysis. Legends are the same as Figure 3

\subsection{Linkography}

Figure 5 shows two typical Linkography generated in the experiment. The left figure visualises that ideas were reacted by backchannel feedbacks from other participants. The right figure visualises that idea was followed by interpretation and backchannel feedbacks first. Then, another idea was proposed in connection with the previous ideas.
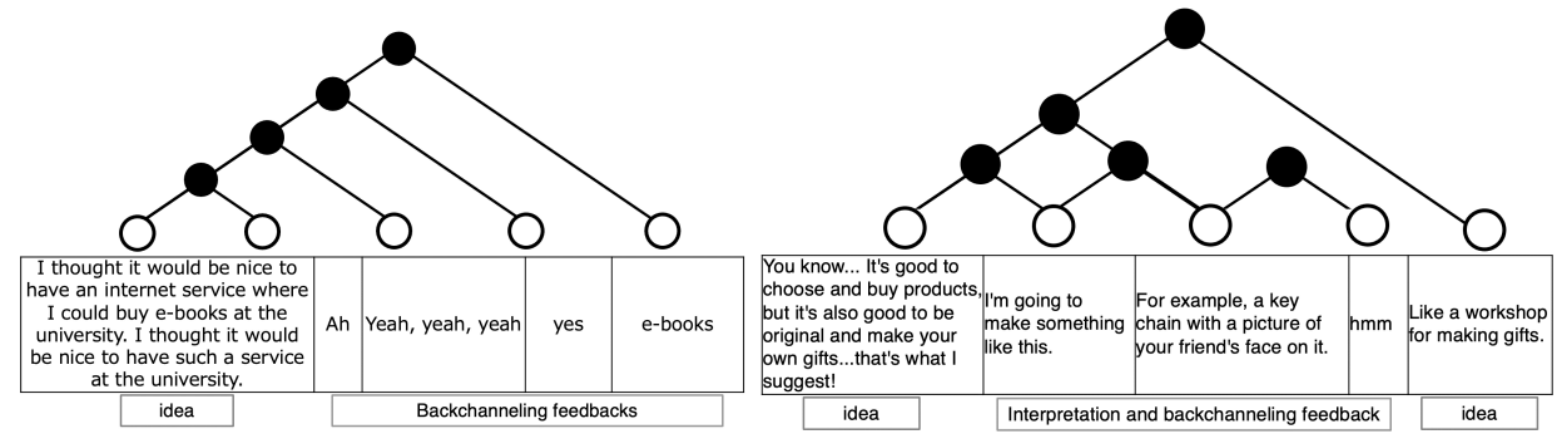

Figure 5. Examples of Linkography results. Left: Backchanneling feedbacks followed a proposition of idea. Right: An idea inspired another idea

Table 2 shows that the average number of total design moves in a session and the number of CM. The result shows that there were no differences in fore-link and back-links in CM4. The ratio of fore-link in the heterogeneous group was slightly smaller than homogeneous groups. In contrast, there seem to be more back-links in the heterogeneous group than in homogeneous groups. However, as the number of groups was not large enough to conduct statistical analysis, the result cannot be generalised.

The number of codes categorised by the defined codes is shown in Table 2. Table 3 shows more utterances coded as "new" in sessions only by art students than in sessions only by engineering students. 
Table 3 also shows that engineering students tended to speak more about knowledge, existing solutions of background information than art students. The average ratio of utterances coded as tangential was similar among art students, engineering students, and heterogeneous groups.

Table 2. The result of critical moves (CM) (Mean (SD): ratio to the total moves)

\begin{tabular}{|c|c|c|c|c|c|}
\hline & \multirow{2}{*}{$\begin{array}{c}\text { Average number } \\
\text { total moves }\end{array}$} & \multicolumn{3}{|c|}{ Average rate (\%) } \\
\hline & & & back-link & fore-link & sum link \\
\hline \multirow{3}{*}{ CM4 } & Art & 221.5(108.19) & $\begin{array}{c}2.5(3.54): \\
0.84\end{array}$ & $\begin{array}{l}\text { 23.5(20.5): } \\
9.48\end{array}$ & $\begin{array}{c}39.0(31.1): \\
16.1\end{array}$ \\
\hline & Engineer & 196.5(74.25) & $\begin{array}{c}1.00(1.41): \\
0.69\end{array}$ & $\begin{array}{c}21.5(16.26): \\
10.1\end{array}$ & $\begin{array}{c}33.5(20.5): \\
16.24\end{array}$ \\
\hline & Diverse & $184.25(50.87)$ & $\begin{array}{c}1.75(1.50): \\
1.05\end{array}$ & $\begin{array}{c}\text { 16.0(4.55): } \\
8.68\end{array}$ & $\begin{array}{c}26.75(6.55): \\
14.65\end{array}$ \\
\hline \multirow{3}{*}{ CM5 } & Art & $221.5(108.19)$ & $\begin{array}{c}1.00(1.41): \\
0.34\end{array}$ & $\begin{array}{c}\text { 16.0(15.6): } \\
6.25\end{array}$ & $\begin{array}{c}27.5(23.3): \\
11.18\end{array}$ \\
\hline & Engineer & 196.5(74.25) & $\begin{array}{c}0.00(0.00): \\
0.00\end{array}$ & $\begin{array}{c}\text { 14.5(10.6): } \\
6.85\end{array}$ & $\begin{array}{c}24.5(17.7): \\
11.6\end{array}$ \\
\hline & Diverse & $184.25(50.87)$ & $\begin{array}{c}0.00(0.00): \\
0.00\end{array}$ & $\begin{array}{c}9.00(3.56): \\
4.84\end{array}$ & $\begin{array}{c}15.5(5.32): \\
8.31\end{array}$ \\
\hline \multirow{3}{*}{ CM6 } & Art & 221.5(108.19) & $\begin{array}{c}0.50(0.71): \\
0.17\end{array}$ & $\begin{array}{c}\text { 11.5(10.6): } \\
4.57\end{array}$ & $\begin{array}{c}17.5(17.7): \\
6.76\end{array}$ \\
\hline & Engineer & 196.5(74.25) & $\begin{array}{c}0.00(0.00): \\
0.00\end{array}$ & $\begin{array}{c}\text { 11.5(6.36): } \\
5.64\end{array}$ & $\begin{array}{c}\text { 17.5(9.19): } \\
8.64\end{array}$ \\
\hline & Diverse & $184.25(50.87)$ & $\begin{array}{c}0.00(0.00): \\
0.00\end{array}$ & $\begin{array}{c}4.75(2.22): \\
2.64\end{array}$ & $\begin{array}{c}9.50(4.80): \\
5.01\end{array}$ \\
\hline
\end{tabular}

Table 3. The result of coding (Mean (SD): ratio to the total moves)

\begin{tabular}{|c|c|c|c|c|c|}
\hline & $\begin{array}{c}\text { The number } \\
\text { of moves per } \\
\text { person }\end{array}$ & New & Incremental & Tangential & Knowledge \\
\hline Art & $221.5(108.19)$ & $\begin{array}{c}11.5(2.12): \\
6.16\end{array}$ & $\begin{array}{c}4.50(6.36): \\
1.51\end{array}$ & $\begin{array}{c}4.50(3.54): \\
1.86\end{array}$ & $\begin{array}{c}13.5(12.0): \\
5.42\end{array}$ \\
\hline Engineer & $196.5(74.25)$ & $\begin{array}{c}2.50(2.12): \\
1.59\end{array}$ & $\begin{array}{c}2.00(2.83): \\
1.39\end{array}$ & $\begin{array}{c}2.50(0.71): \\
1.30\end{array}$ & $\begin{array}{c}32.5(30.4): \\
14.5\end{array}$ \\
\hline Diverse & $184.25(50.87)$ & $\begin{array}{c}11.5(6.45): \\
7.21\end{array}$ & $\begin{array}{c}1.75(1.71): \\
1.10\end{array}$ & $\begin{array}{c}2.00(1.15): \\
1.09\end{array}$ & $\begin{array}{c}20.3(14.1): \\
10.6\end{array}$ \\
\hline
\end{tabular}

\section{DISCUSSION}

The analysis results in creativity and questionnaire show that the diversity increased the attention of engineering students toward originality of ideas. However, the creativity of engineering students in heterogeneous group did not differ from them in homogeneous groups. On the other hand, art students generated ideas of less originality in heterogeneous conditions than in homogeneous conditions. The result is consistent with the lower degree of innovative outcomes of diversified groups on average [2]. These results imply that in short-term conditions, diversity had negative impacts on outcomes. We might find different results when the duration of experiments is longer. Investigation of the causes of the differences is a direction of future studies on design education of multi-disciplinary team.

The Linkography result successfully visualised the dynamics of discussion of different educational backgrounds. The difference in discussion styles between art students and engineering students might be why lower creative outcomes of diversified groups on average [2]. The difference implies that teams of diversified groups suffer from process conflicts which occurred due to different thought in how team processed projects [19]. The barriers might be able to be overcome by offering a discussion process that is acceptable for all educational backgrounds, such as design thinking [20].

The result shows that there were fewer critical links in the heterogeneous group than in homogenous groups. It implies that brainstorming might not be a suitable method for encouraging collaboration among different educational backgrounds. It also implies that the short-term period's experiment may 
not be a good experiment setup to investigate cross-disciplinary collaborations' difficulties. Observation of team design projects might be a useful research strategy to investigate the difficulties.

\section{CONCLUSIONS}

This study experimented with comparing outcome creativity, participants' perception, and group discussion dynamics of students of two different educational backgrounds. The result shows that diversity in a team might hinder group discussion due to differences in discussion styles. It also implies that brainstorming might not be a good method to encourage collaboration between people having different educational backgrounds. The findings of this study are a first step in visualising the difficulties of cross-disciplinary collaboration.

\section{ACKNOWLEDGEMENT}

This research was supported by the Japanese Society for the Promotion of Science, KAKENHI Grant Number 20K20116.

\section{REFERENCE}

[1] Wright N. and Wrigley C. Broadening design-led education horizons: conceptual insights and future research directions. International Journal of Technology and Design Education, 2019. 29(1): pp. 1-23.

[2] Fleming L. Perfecting cross-pollination. Harvard business review, 2004. 82(9): pp. 22-24.

[3] Falk D. R. and Johnson D. W. The effects of perspective-taking and egocentrism on problem solving in heterogeneous and homogeneous groups. The Journal of Social Psychology, 1977. 102(1): pp. 63-72.

[4] Horwitz S. K. and Horwitz I. B. The effects of team diversity on team outcomes: A meta-analytic review of team demography. Journal of management, 2007. 33(6): pp. 987-1015.

[5] Backes-Gellner U. and Veen S. Positive effects of ageing and age diversity in innovative companies - large-scale empirical evidence on company productivity. Human Resource Management Journal, 2013. 23(3): pp. 279-295.

[6] Mostert S. G. S. I. Creativity and sex composition: An experimental illustration. European Journal of Work and Organizational Psychology, 1997. 6(2): pp. 175-182.

[7] Menold J. and Jablokow K. Exploring the effects of cognitive style diversity and self-efficacy beliefs on final design attributes in student design teams. Design Studies, 2019. 60: pp. 71-102.

[8] Oxman R. Think-maps: teaching design thinking in design education. Design studies, 2004. 25(1): pp. 63-91.

[9] Goldschmidt G. Linkography: Assessing Design Productivity. 1990.

[10] Goldschmidt G. The designer as a team of one. Design Studies, 1995. 16(2): pp. 189-209.

[11] Goldschmidt G. and Weil M. Contents and structure in design reasoning. Design issues, 1998. 14(3): pp. 85-100.

[12] Goldschmidt G. Linkography: unfolding the design process. 2014: Mit Press.

[13] Blom N. and Bogaers A. Using Linkography to investigate students' thinking and information use during a STEM task. International Journal of Technology and Design Education, 2020. 30(1): pp. $1-20$.

[14] Hatcher G. et al. Using Linkography to compare creative methods for group ideation. Design Studies, 2018. 58: pp. 127-152.

[15] Cronbach L. J. Coefficient alpha and the internal structure of tests. Psychometrika, 1951. 16(3): pp. 297-334.

[16] Mullen B., Johnson C., and Salas E. Productivity loss in brainstorming groups: A meta-analytic integration. Basic and Applied Social Psychology, 1991. 12(1): pp. 3-23.

[17] Kan J. W. and Gero J. S. Quantitative methods for studying design protocols. 2017: Springer.

[18] Clancy P. M. et al. The conversational use of reactive tokens in English, Japanese, and Mandarin. Journal of Pragmatics, 1996. 26(3): pp. 355-387.

[19] Paletz S. B. F., Chan J., and Schunn C. D. The dynamics of micro-conflicts and uncertainty in successful and unsuccessful design teams. Design Studies, 2017. 50: pp. 39-69.

[20] Brown T. Design thinking. Harvard business review, 2008. 86(6): pp. 84. 